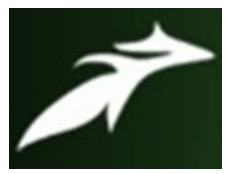

Jyoti et al, International Journal of Advances in Agricultural Science \& Technology,

Vol.8 Issue.12, December-2021, pg. 32-38

ISSN: 2348-1358

Impact Factor: 6.057

NAAS Rating: 3.77

\title{
Knowledge of Utilization of Citrus Fruit Peels after Consumption among Random Selected Population at Sonepat District in Haryana State
}

\author{
Jyoti $^{1}$; Dr. Veena ${ }^{2}$ \\ ${ }^{1} \mathrm{Ph} . \mathrm{D}$ (Food \& Nutrition), Bhagat Phool Singh Mahila University, Sonepat, Haryana, India \\ jyotimalik686@gmail.com \\ ${ }^{2}$ Principal, Institute of Higher Learning, Bhagat Phool Singh Mahila University Sonepat, Haryana, India \\ principalbpsihl@gmail.com \\ DOI: 10.47856/ijaast.2021.v08i12.003
}

\begin{abstract}
Citrus is an important part of fruit family. It belonging to the family Rutaceae, which include fruits such as orange, mandarin, lime, lemon, sour orange and grapefruit, pomelo appear as a well known promising source of multiple beneficial nutrients for human beings. Processing of citrus by-products (peel, pulp, and seed) potentially represents a rich source of phenolic compounds and dietary fiber, by consumption of citrus fruit the large amount of peel waste produced. These citrus fruit residues, which are generally discarded as waste in the environment, they can act as potential nutraceutical resources. Such comprehensive Utilization of Citrus By-products provides comprehensive knowledge and information on the development and utilization of citrus by-products, including (types, preparation, and determination) of their main functional components. One of the most popular fruits in the world, from the point of processing is citrus fruits by which produces citrus peel, a primary by-product. Current statuses of citrus peel pollute the environment and waste resources so eco-friendly solutions are sought. This review systematically summarized the knowledge of utilization of citrus peel, which generally discarded as waste by consumer after consumption of fruit.

Keywords: Citrus, Citrus peel, Nutraceuticals, Utilization, Phenolic, By - Product, Eco - Friendly.
\end{abstract}

\section{Introduction}

Citrus fruit is one of the major horticultural crops grown in all over world, and they are the most traded horticultural commodity of the world. Origin of citrus fruits is still under debate, but it is believed that it originated from Southeast Asia and spread to the other parts of the world. Citrus crop is grown in developed and developing both countries as well. Citrus fruits constitute a source of vitamin C. Brazil, the Mediterranean countries, China, and the United States account for about two-thirds of the total citrus production of citrus fruit. From the last 30 years, there has been a steady increase in the per capita consumption of citrus fruits worldwide. North America country has the highest per capita consumption of citrus fruits in the world followed by South America and Europe. According to FAO, fresh citrus fruit consumption is decreasing in the developed countries; they used tetra pack juice instead of fresh fruit while some of the developing countries are showing an increase in consumption. Great variation exists in the types of citrus fruits produced and consumed throughout the different parts of the world. Oranges occupy the major portion of world citrus production followed by mandarins and other citrus spices. Oranges form the majority of the citrus crop which produced in the United States. About 1/3 of the citrus fruits produced globally are used for processing (like powder). 


\section{$\vec{x}$ \\ Jyoti et al, International Journal of Advances in Agricultural Science \& Technology, Vol.8 Issue.12, December-2021, pg. 32-38}

ISSN: 2348-1358

Impact Factor: 6.057

NAAS Rating: 3.77

\subsection{CITRUS FRUITS - Composition and Characterization}

Citrus fruits are one of the largest fruit crops of the world. About 30\% of citrus fruits are processed to obtain various products, mainly juice and candy. Similarly, the citrus industry is also the second largest fruit-processing industry, that surpassed again by the grape industry, which mainly produces wine. Neither orange juice nor wine can be considered essential foods but they do have an important role in our lives to maintain human health.

Although citrus fruits have been consumed since ancient times and also used for processing, as it is known today, was not possible until thermal treatment (to inactivate enzymes and microorganisms) and concentration processes were commercially available in particular area. Since then, the citrus industry has developed rapidly, becoming prominent among food industries and recently it's growing very fast.

Although consumption of fresh citrus fruits is popular in all producing countries and processed products must still be considered almost as luxury products. Breakfast with citrus fruit include orange juice is only common in developed countries. Thus, citrus industries process value-added products whose quality, nutritional characteristics, and purity are appreciated which can be used everywhere. Since these aspects are closely related to composition, the analysis of citrus constituents is a frequent subject of research work, supported by governments and industries and institution also. This review covers the most important aspects of citrus fruit composition, its relationship to nutritional value, and its importance for product authentication.

\subsection{Medicinal properties of citrus fruits}

Citrus fruits such as mandarin, pomelo, orange, lime, lemon, and grapefruit have been recognized as having high contents of bioactive compounds from citrus family. The pulp and the peel of fruits contain folate, vitamin C, dietary fiber, and bioactive compounds such as flavonoids. Flavonoids are widely distributed in aromatic plants such as mint and tea but they are present in high concentrations in citrus fruits and their peels.

Citrus peel has potential as a source of medicinal compounds because it contains carotenes, essential oils, pectin, and a range of polyphenolic compounds. Epidemiological studies have shown that high consumption of fruits and vegetables (>400 g/d) can reduce cancer risk by $\geq 20 \%$. The Mediterranean diet is rich in fruit pulp and juice, and associated with high intake of fiber, antioxidants, and polyphenol compounds are linked with lower cancer risk.

The medicinal use of citrus peels can be traced from 10th century; the biological activities of specific chemicals within the peel have only recently been characterized. Citrus peels are rich in polyphenolic compounds, which are secondary plant metabolites with diverse and an essential biological functions.

Polyphenolic compounds consist of various classes of bioactive compounds including flavonoids, limonoids, coumarins, phenolic acids, terpenoids, tannins, stilbenes, lignans, and carotenoids. They contain heterocycles including aromatic rings with hydroxyl groups in their basic structure and founded in the Free State or as glycosides. Flavonoids are likely to be key bioactive compounds in citrus peel, particularly in terms of their anticancer activity as well as in the prevention of infectious and degenerative diseases (in body). Although it is appealing to identify specific molecules with high anticancer activity, there is growing evidence to suggest synergy between bioactive molecules in citrus fruit peel. Whole Citrus fruit have been shown to have higher anticancer activity and their peel has chemo preventive agents, as well as to leverage their antiatherogenic, anticarcinogenic, anti-inflammatory, anticancer, antidiarrheal, and antimicrobial properties. 


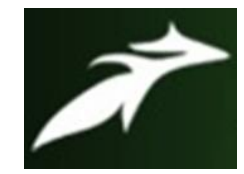

Jyoti et al, International Journal of Advances in Agricultural Science \& Technology,

Vol.8 Issue.12, December-2021, pg. 32-38

ISSN: $2348-1358$

Impact Factor: 6.057

NAAS Rating: 3.77

\subsection{Functional Component of Citrus Fruit Peel}

Peels of citrus fruits contains two types of natural pigments with different characteristics such as lipid-soluble carotenoids and water-soluble yellow pigments. Representative compounds are a water-soluble pigment and a lipidsoluble pigment, both of has high safety and excellent nutritional and medicinal values. This pigment derived from citrus peel which is an important natural pigment, major component mixture of carotenoids that can replace synthetic pigments in food colorings. Carotenoids comprise many lipid-soluble plant pigments, which contain 40 carbon atoms and 8 isoprenoid units. Carotenoid contents and compositions are determinants from the color of citrus peel.

\section{Methodology}

Research was conducted at Institute of Higher Learning Department of BPSMV University situated at Sonepat District of Haryana State, India.

\subsection{Data Collection}

Randomly selected people (male and female) of different age group of Sonepat district for data collection.

2.2 Sample size -: total 100 no. of participate (50 male \& 50 female)

\subsection{Method of Data Collection}

Questionnaire method was selected for data collection.

\subsection{Research Design}

Descriptive research design used for study.

\subsection{Type of variable}

Dependent variable (knowledge and utilization of fruit peels)

Independent variable (Name, Age, Sex, Place, Educational Profile, Occupation)

\subsection{Statically analyzed}

The data was analyzed by using various statically parameter. 


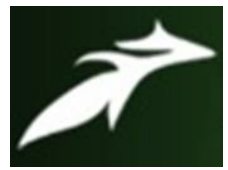

Jyoti et al, International Journal of Advances in Agricultural Science \& Technology,

Vol.8 Issue.12, December-2021, pg. 32-38

ISSN: 2348-1358

Impact Factor: 6.057

NAAS Rating: 3.77

\section{Result and Discussion}

3.1 Table 1-: Representation of age graph according to sex

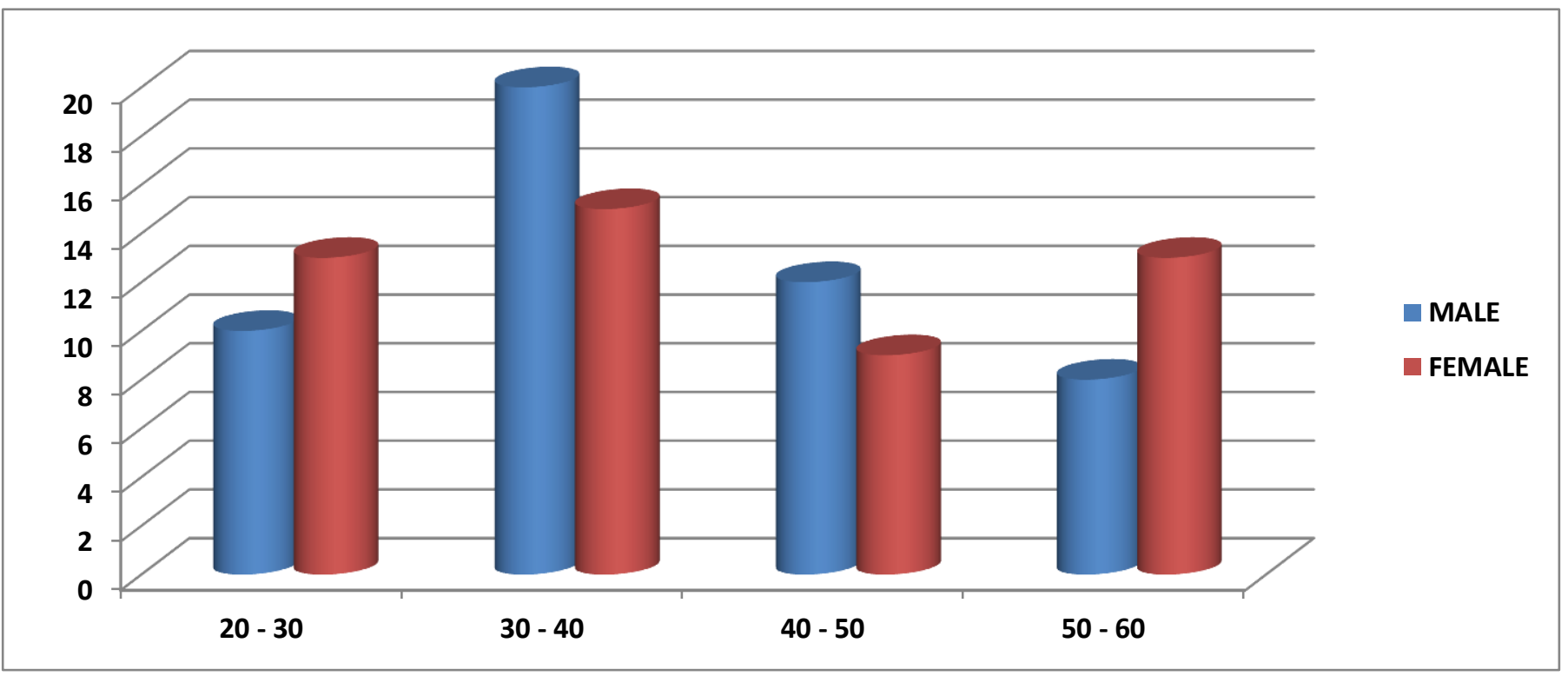

3.2 Table 2 -: Representation of occupation

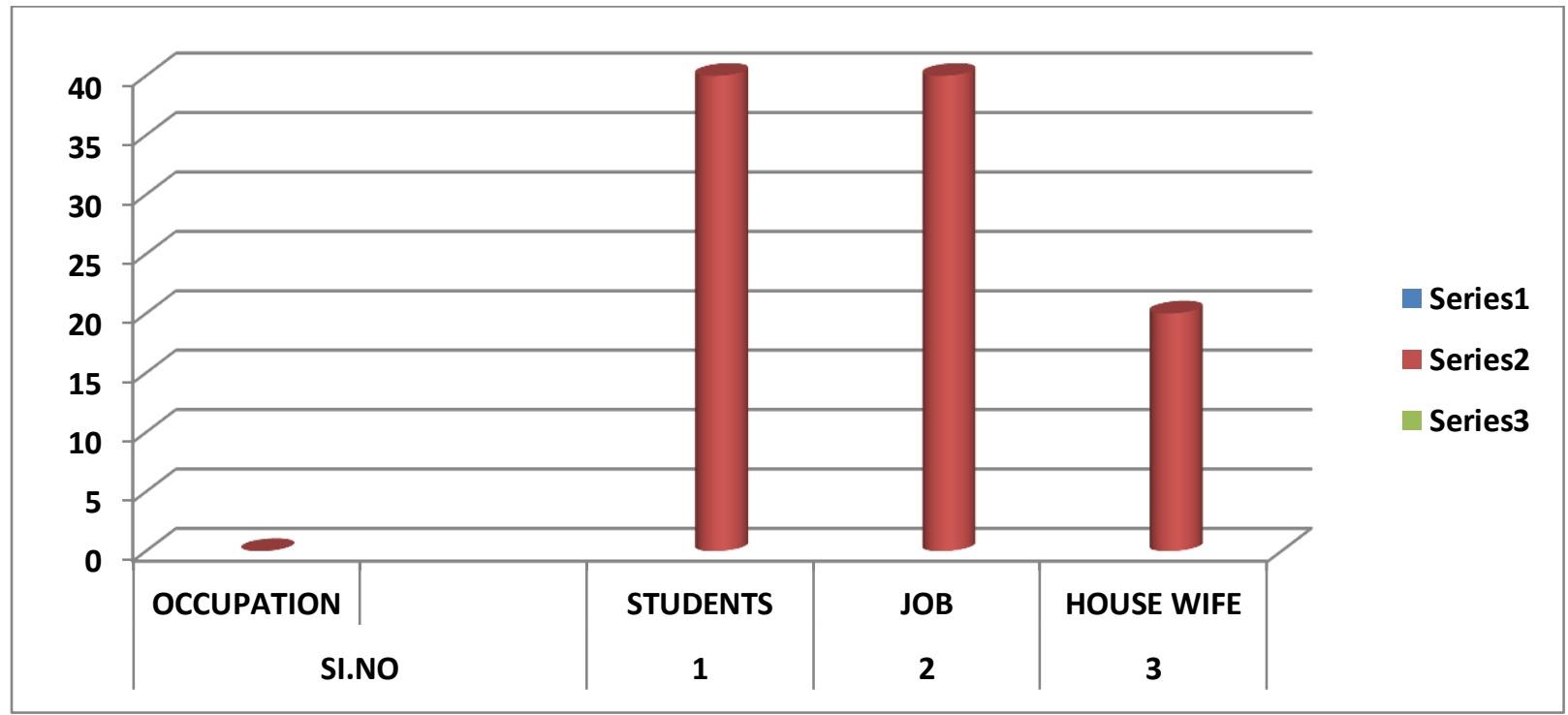




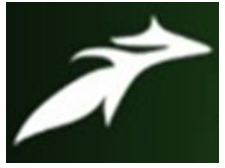

Jyoti et al, International Journal of Advances in Agricultural Science \& Technology,

Vol.8 Issue.12, December-2021, pg. 32-38

ISSN: 2348-1358

Impact Factor: 6.057

NAAS Rating: 3.77

3.3 Figure 3 -: Knowledge of citrus fruits health benefit

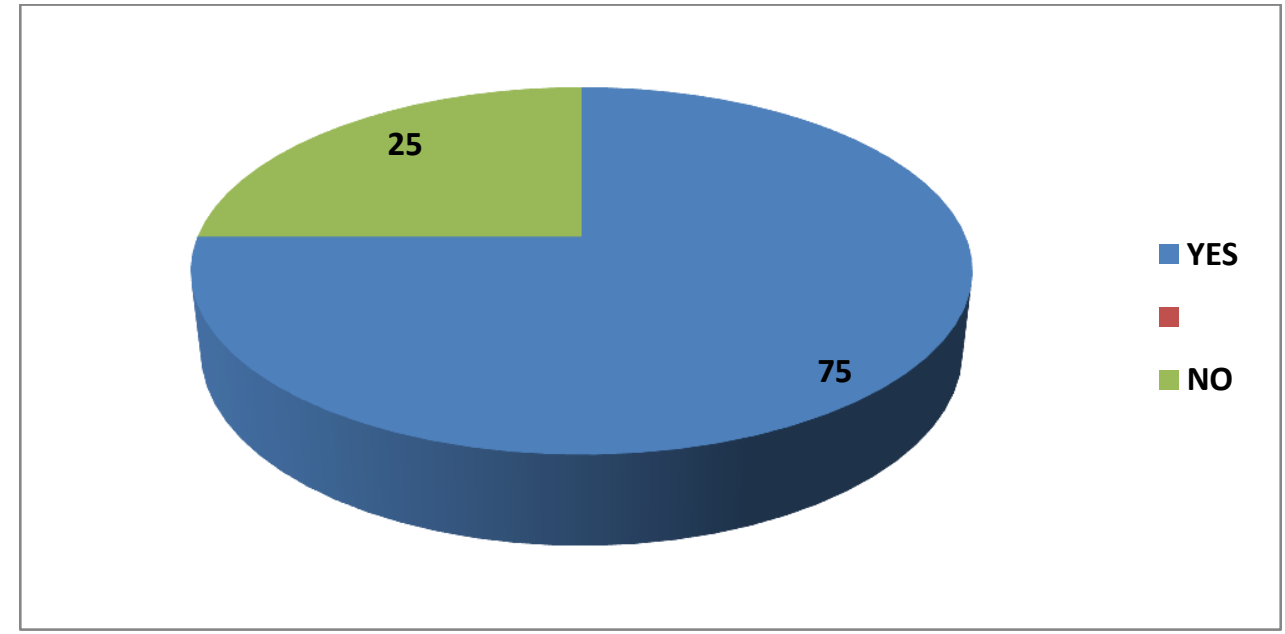

3.4 table 4 - : Knowledge of utilization of fruits peels

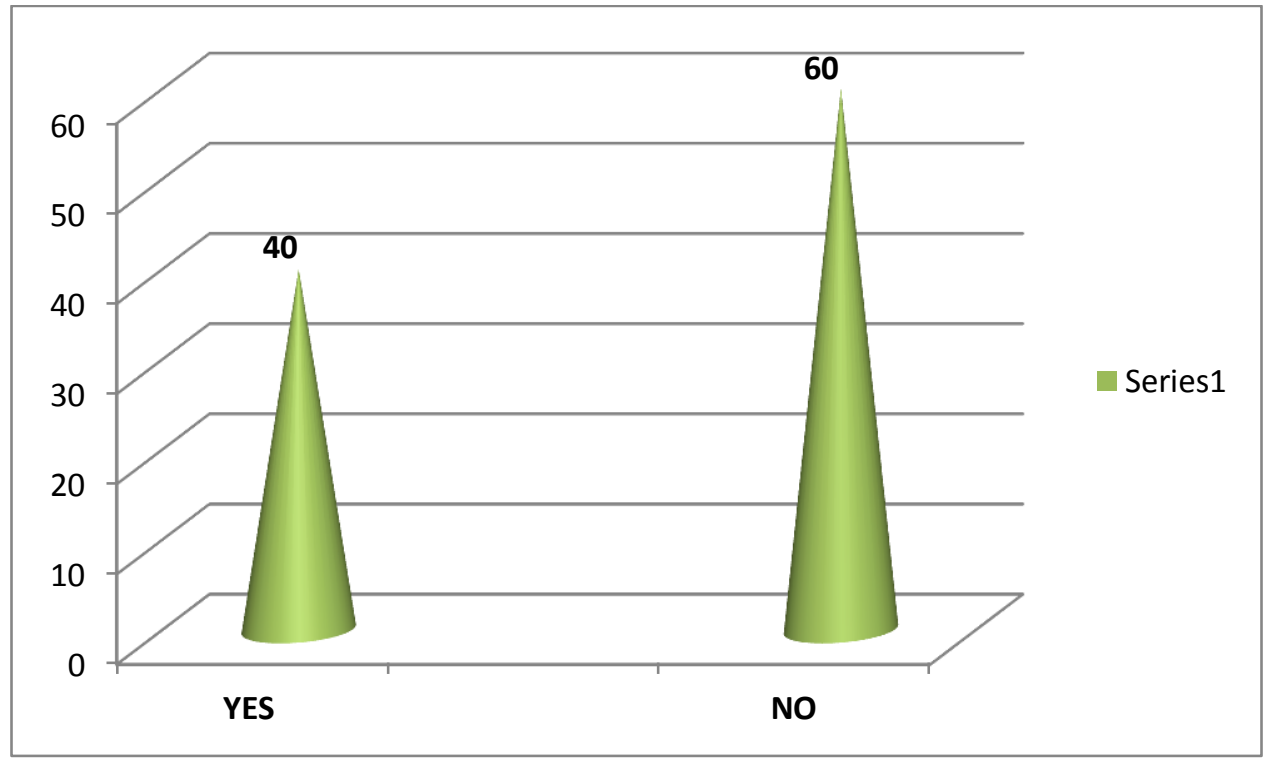




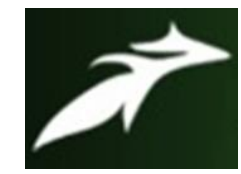

Jyoti et al, International Journal of Advances in Agricultural Science \& Technology,

Vol.8 Issue.12, December-2021, pg. 32-38

ISSN: 2348-1358

Impact Factor: 6.057

NAAS Rating: 3.77

\section{5 table 5 -: Information of utilization and wastage of citrus fruit peels}

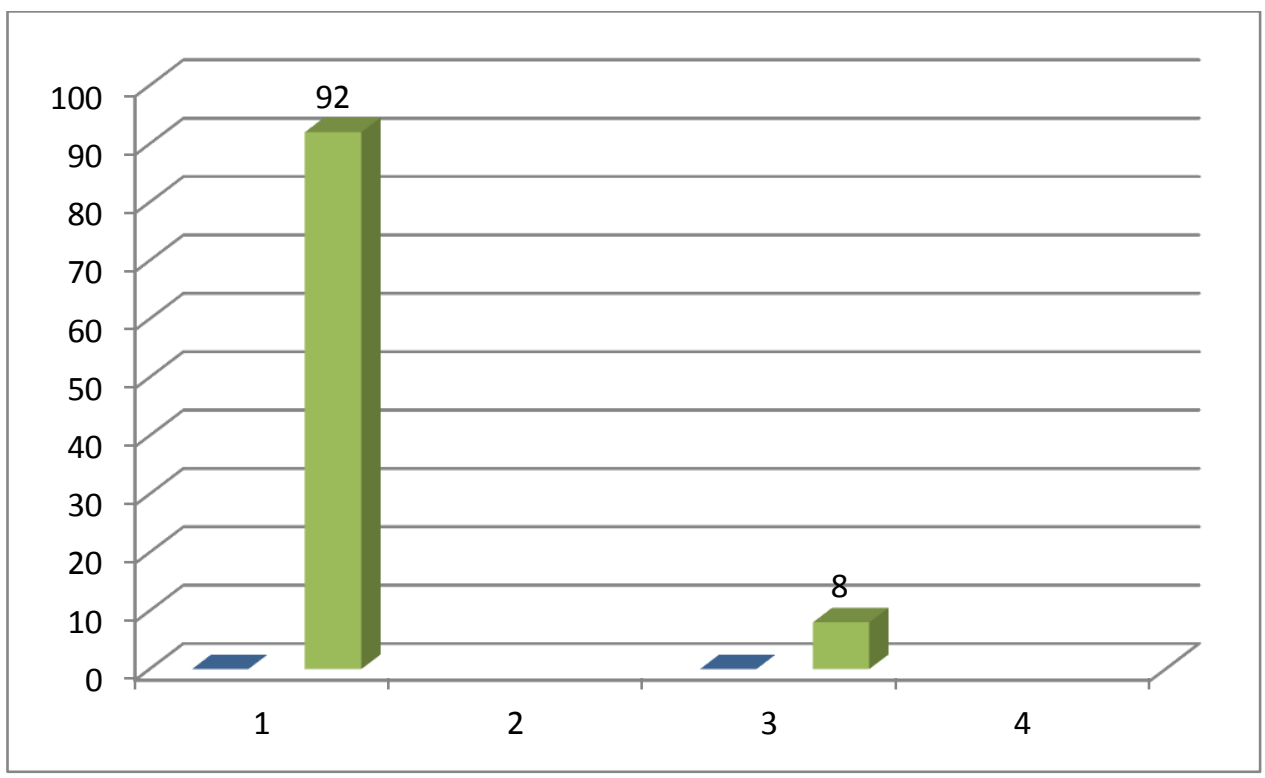

\section{Conclusion}

Overall conclusion of the research was that most of the population was using citrus fruit. They know about various health benefits in the body. Women know about the cosmetic use from citrus fruit peels. But they are not interested to utilize peel at their home. Selected people use readymade peels powder. Recent many research concerning functional properties of citrus by-products (peels, seeds, pilp) especially peel has added to our knowledge. Due to the low cost and easily availability of fruit residues which would be discarded as waste in the environment after use should be regarded as potential nutraceutical resources, capable of offering significantly low-cost, nutritional dietary supplements. These are rich in bioactive compounds, these unwanted cast-offs of manufacturing could be recycled as value added food supplements, that provide advantageous dietary fibre and polyphenols which are useful for body. Such kind of product serve as non-caloric bulking agents, enhance water and oil retention, improve emulsion and could prevent us from a wide range of diseases caused due to oxidative stress. The extracts from fruit peel and pulp hold promise in food industry as sources of bioactive compounds. An established use of the citrus peel would also help to alleviate pollution problems that caused because of the poor disposal of such residues. 


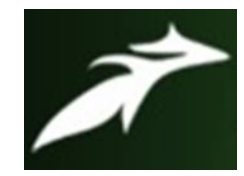

Jyoti et al, International Journal of Advances in Agricultural Science \& Technology, Vol.8 Issue.12, December-2021, pg. 32-38

ISSN: 2348-1358

Impact Factor: 6.057

NAAS Rating: 3.77

\section{References}

[1]. Osarumwense PO, Okunrobo LO, Uwumarongie-ILORI EG, 2013, Phytochemical screening, proximate and elemental analysis of Citrus sinensis peels, Journal of Applied Sciences \& Environmental Management, pp 47-50.

[2]. Pandey AK, Ojha V, 2014, Precooking processing of bamboo shoots for removal of anti-nutrients Journal of Food Science \& Technology, pp. 43-50.

[3]. Pfaltzgraff LA, Cooper EC, Budarin V, Clark JH, 2013, Food waste biomass: A resource for high-value chemicals. Green Chemistry, Blog, pp. 307-314.

[4]. Rgazzi E, Vetnese G, 1973, Free radical tissue damage; protective role of layer chromatography separation,. Journal of Chromatography, pp. 369-375.

[5]. Santana-Méridas O, González-Coloma A, Sánchez-Vioque , 2012, Agricultural residues as a source of bioactive natural products, Phytochemical Rev, 11. Pp. 447-466.

[6]. Schieber A, Stintzing FC, Carle R, 2001, By-products of plant food processing as a source of functional compounds-Recent development,. Trends in Food Science \&. Technology, 12, 11, pp. 401-413.

[7]. Sharma S, 2007, Experiments and techniques in biochemistry New Delhi, Galgotia Publication Pvt Ltd.

[8]. Shie PH, Lay HL, 2013, Component analysis and antioxidant activity of Citrus lemon, Academia Journal of Medicinal Plants, 1,3, pp 049-058.

[9]. Syed HM, Pravin UG, Machewad G, Pawar S, 2012, Studies on preparation of squash from sweet orange, Open Access Scientific Report, 1,6, pp. 2-3.

[10]. Bamise TC, Oziegbe EO, 2013, Laboratory analysis of $\mathrm{pH}$ and neutralizable acidity of commercial citrus fruits in Nigeria, Advances in Biological Research, 7,2, pp. 72-76.

[11].Charles T, Paa-Nii T, Johnson, Ted S, Matilde M, Theo T, 2013, Physicochemical, proximate and sensory properties of pineapple (Ananas sp.) syrup developed from its organic side-stream, Food and Nutrition Sciences, pp. 163-168.

[12].Glasscock SJ, Axelson JM., Palmer JK, Phillips JA, Taper LJ, 1982, Microwave blanching of vegetables for frozen storage, Home Economics Research Journal, 11,2, pp. 149-158.

[13].Janati F, Beheshti HR, Feizy J, Fahim NK, 2012, Chemical composition of lemon and peels is consideration as animal food, 37,5, pp. 267-271.

\section{A Brief Author Biography}

$\mathbf{1}^{\text {st }}$ Jyoti - A research scholar, pursuing Ph.D (Food \& Nutrition) from Institute of Higher Learning from Bhagat Phool Singh Mahila University, Khanpur Kalan, Sonepat, Haryana, area of interest is food science.

$\mathbf{2}^{\text {nd }}$ Dr. Veena - Principal of Institute of Higher Learning from Bhagat Phool Singh Mahila University, Khanpur Kalan, Sonepat, Haryana, 